\title{
Alberta launches physician assistant pilot project
}

A lberta Health has hired two physician assistants in each of the province's five health care zones as part of a pilot project to see if they are a viable way to increase patients' access to health care providers.

"From a physician's standpoint, they're welcomed with open arms," says Dr. Neil Gibson, medical director of the Alberta Demonstration Project. "They fill a lot of gaps."

Physician assistants (sometimes called physician extenders) can help Alberta Health meet its major goals of extending health care to the underserviced and establishing primary care networks in rural areas, Gibson says.

Though the profession itself has been around for some time — the Canadian Forces began training physician assistants in 1984 - civilian physician assistants are relatively new in Canada. Demand for their ser-

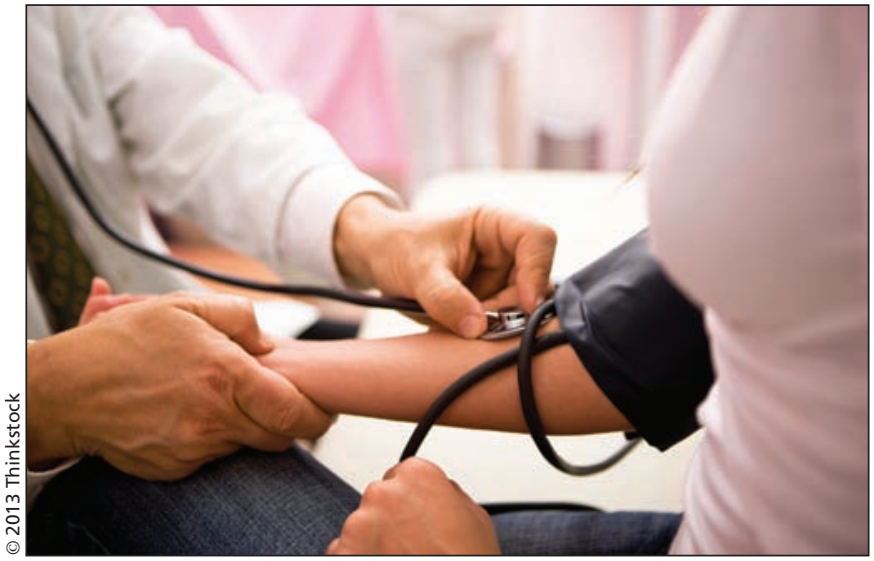

Physician assistants work under the supervision of physicians and provide a wide range of health services in various clinical settings. supervision of a physician, whose scope of practice they mirror. Because of this, physician assistants can fill many roles. The supervising physician delegates tasks to the physician assistant, and like doctors, physician assistants can specialize and work in a wide array of settings. in Bozeman, which she attended on a ski scholarship. In Montana, she encountered physician assistants every time she went to the student clinic. The United States has been training and employing physician assistants since 1965.

"I had no idea what they were at the time," Lattimer says. "But they were totally competent health care providers and they increased access to care. We never had any issues getting appointments at the student health clinic because there were so many PAs employed there."

After working in the US for a year, Lattimer returned to Canada and decided to enroll in the University of Manitoba's physician assistant program. She would like to work in surgery or emergency medicine, but says she'll be happy wherever she lands.

"We're all so passionate about medicine. That's the reason we chose to be in this class in the first place, so I vices exceeds supply. About 350 physician assistants, or "PAs," practise in Canada, 180 of them in Ontario, according to the Canadian Association of Physician Assistants (CAPA).

The University of Manitoba in Winnipeg and McMaster University in Hamilton, Ontario, began training physician assistants in 2008. The University of Toronto in Ontario began its program in 2010. All three programs run for six semesters, or two uninterrupted years, and require previous undergraduate work.

Before these programs, the only formal physician assistant training in Canada was through the Canadian Forces Health Services Training Centre. Alberta has been able to draw on a pool of Canadian Forces-trained physician assistants, but "it's a finite pool," says Gibson, adding that western Canada needs its own training program.

Physician assistants work under the
They can, for example, see patients in a family practice, assist in surgery, make treatment plans with emergency department patients and perform medical procedures. They have a "negotiated autonomy" with their supervising physician, says Natalie St-Pierre, CAPA's communications and marketing manager.

The University of Manitoba graduates 12 physician assistants per year from its 24-month program. Student Amy Lattimer has finished her year of classroom learning and begun her clinical year as a physician assistant. She will spend the year rotating through 12 placements, ranging from family practices to emergency rooms.

"The class ahead of us just graduated, and they've all signed contracts already," says Lattimer.

Lattimer completed her undergraduate degree at Montana State University don't think any of us will be complaining too much just as long as we have a job in this field," she says.

Manitoba struggles with physician retention and access to care in rural areas. In 2010, the province committed to providing every Manitoban with access to a family doctor by 2015 . Physician assistant students at the University of Manitoba spend the greatest chunk of their clinical year in family practice, positioning them to help the government meet its commitment.

Meanwhile, while Alberta is doing "due diligence" by launching the pilot project, Gibson says he foresees physician assistants becoming a regular part of many health care teams in Alberta in the future. "The bottom line is I don't think there's any doubt they will help." - Catherine Cross, CMAJ

CMAJ 2013. DOI:10.1503/cmaj.109-4605 